\title{
Seismic expression of miocene carbonate platform and reservoir characterization through geophysical approach: application in central Luconia, offshore Malaysia
}

\author{
Yasir Bashir ${ }^{1,2}$ (I) Muhammad Amir Faisal $^{2} \cdot$ Ajay Biswas $^{2} \cdot$ Amir abbas Babasafari $^{2} \cdot$ Syed Haroon Ali $^{3}$. \\ Qazi Sohail Imran ${ }^{2} \cdot$ Numair Ahmed Siddiqui $^{2} \cdot$ Muhsan Ehsan ${ }^{4}$
}

Received: 2 December 2020 / Accepted: 4 March 2021 / Published online: 1 April 2021

(C) The Author(s) 2021

\begin{abstract}
A substantial proportion of proven oil and gas reserves of the world is contained in the carbonate reservoir. It is estimated that about $60 \%$ of the world's oil and $40 \%$ of gas reserves are confined in carbonate reservoirs. Exploration and development of hydrocarbons in carbonate reservoirs are much more challenging due to poor seismic imaging and reservoir heterogeneity caused by diagenetic changes. Evaluation of carbonate reservoirs has been a high priority for researchers and geoscientists working in the petroleum industry mainly due to the challenges presented by these highly heterogeneous reservoir rocks. It is essential for geoscientists, petrophysicists, and engineers to work together from initial phases of exploration and delineation of the pool through mature stages of production, to extract as much information as possible to produce maximum hydrocarbons from the field for the commercial viability of the project. In the absence of the well-log data, the properties are inferred from the inversion of seismic data alone. In oil and gas exploration and production industries, seismic inversion is proven as a tool for tracing the subsurface reservoir facies and their fluid contents. In this paper, seismic inversion demonstrates the understanding of lithology and includes the full band of frequency in our initial model to incorporate the detailed study about the basin for prospect evaluation. 3D seismic data along with the geological \& petrophysical information and electrologs acquired from drilled wells are used for interpretation and inversion of seismic data to understand the reservoir geometry and facies variation including the distribution of intervening tight layers within the Miocene carbonate reservoir in the study area of Central Luconia. The out-come of the seismic post-stack inversion technique shows a better subsurface lithofacies and fluid distribution for delineation and detailed study of the reservoir.
\end{abstract}

Keywords Seismic expression $\cdot$ Inversion $\cdot$ Tight layer $\cdot$ Electrofacies $\cdot$ Impedance

\section{Introduction}

In southeast Asia, the deposition of tropical shallow-water carbonates including reefs was extensive in the tectonically complex region during the Tertiary time (Epting 1987; Wil-

Yasir Bashir

dryasir.bashir@live.com; Yasir.bashir@usm.my

1 School of Physics, Geophysics Section, Universiti Sains Malaysia, 11800 USM Penang, Malaysia

2 Centre for Seismic Imaging (CSI), Geosciences, Universiti Teknologi PETRONAS, Perak, Malaysia

3 Department of Earth Sciences, University of Sargodha, Sargodha 40100, Pakistan

4 Department of Earth and Environmental Sciences, Bahria University, Islamabad, Pakistan son 2002). The isolated Miocene carbonate reefs are widespread in the Luconia province, offshore Sarawak, Malaysia. In this basin over 200 carbonate platforms ranging in size from a few to more than $200 \mathrm{~km}^{2}$ have been mapped (Zampetti et al. 2004). The structural evolution of basin, chronostratigraphic and lithostratigraphic subdivisions have been published by different workers both from industry and academia (Epting 1980, 1987; Vahrenkamp 1998, 2000; Bracco Gartner 2000; Lunt and Madon 2017). The hydrocarbon exploration activities by E\&P companies have proved

,

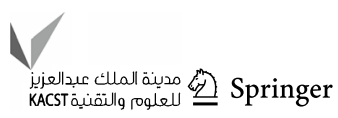


that the Miocene reefal carbonates in Sarawak Basin contain numerous gas reservoirs of economic importance.

To address the issues of reservoir heterogeneity and fluid distribution in the carbonate reservoir, it is prudent to apply the seismic inversion techniques to reduce the exploration risk and informed decision-making for field development. Seismic diffraction imaging has contributed to an enhancement in the quality of seismic in carbonate reservoirs, whereas seismic inversion is useful for a better understanding of reservoir facies and impedance contrast in carbonates (Bashir et al. 2019). Seismic inversion is used to extract temporally and spatially variable physical parameters representing the subsurface geological properties and the fluid contents in the prospective reservoir to assist in hydrocarbon exploration and field development. Quantitative interpretation of reservoir parameters with seismic inversion algorithm is an integral part of reservoir characterization and sweet spots identification for field development and strategic well placement, both injector and producer wells, for commercial exploitation of the reservoir.

The Central Luconia province in the offshore Sarawak Basin of Malaysia witnessed prolific carbonate deposition during Miocene with a high level of exploration success. The Miocene carbonate play is the primary target for hydrocarbon exploration in Central Luconia province with many commercial gas discoveries and upside exploration potential (Janjuhah et al. 2018). A majority of the remaining exploration potential in Sarawak Basin is contained in the Carbonate reservoir which is much more difficult to explore and develop as imaging is complicated mainly due to variation of depositional facies and reservoir heterogeneity caused by diagenetic changes. It has been observed that carbonate reservoirs can display highly varying properties within a small section of the reservoir depending on depositional facies and post-depositional diagenetic changes. As a result, it is difficult to characterize the reservoirs and assess the risks of field performance. Identification of growth architecture of reefs, facies variation in time and space, and diagenetic imprints with special reference to karstification events are important for field development, production optimization, and future exploration success in carbonates of the Central Luconia platform.

Miocene carbonates of Central Luconia in offshore Sarawak Basin are the major gas producer, containing about $60 \%$ of the Malaysian gas reserves. Carbonates of Central Luconia are characterized by internal heterogeneity and complex geometric relations with off-platform strata on their flanks. It is important to understand this complex depositional setting of Central Luconia carbonates, the architecture of Miocene isolated carbonate platforms, and reservoir heterogeneity caused by diagenetic changes for hydrocarbon exploration and field development. This research includes the integrated studies of seismic, geological, and petrophysical properties to improve the understanding of subsurface reservoir and fluid flow models for reservoir characterization and field development. Recent advancements in seismic acquisition and processing have contributed to an enhancement in the quality of seismic data for better subsurface imaging. Seismic inversion can help for a better understanding of reservoir properties, impedance contrast, and crucial information about the 3D geometry and petrophysical properties of the reservoir facies, characteristics of fluid-flow units.

The study area is located about $170 \mathrm{~km}$ north of Bintulu in a water depth of $91.0 \mathrm{~m}$ in the offshore Sarawak Basin of Malaysia in the eastern part of the Luconia Province and west of the West Baram Hinge Line (Fig. 1). Interpretation of geological and geophysical data have identified different platform growth stages across the study area due to eustatic sea-level changes, and variations in subsidence caused by regional and local tectonics. Cyclic deposition of carbonates and lateral facies variation due to depositional conditions with intermittent subaerial exposures have contributed to reservoir heterogeneity. Preserved porosity types and their distribution are quite varied in Luconia carbonates due to its facies association and multistage diagenetic episodes that need special attention for field development. Facies analysis has identified the reservoir properties of carbonates that have been affected by post-depositional diagenetic processes by periodic exposures due to sea-level fluctuations and contributed to reservoir heterogeneity. Diagenetic imprints in the form of karstification have been recorded in a carbonate reservoir in different fields of Central Luconia due to intense dissolution in the vadose zone with periodic exposures of relatively long duration (Vahrenkamp et al. 2004). In this study, an integrated approach is made by applying inversion data to address the issues related to facies variation and reservoir heterogeneity for exploration and development in Central Luconia carbonates.

The field is structurally simple with platform-type carbonate deposition during Miocene. The reservoir unit shows cyclic deposition of carbonates controlled by relative sealevel fluctuations. The Miocene carbonates are overlain by younger siliciclastic sediments. The field is structurally welldefined with an elongation in an NNE -SSW direction. The seismic-to-well ties are reasonably good and allow for the identification of the top Carbonate and the intra-reservoir seismic events. The top Carbonate is well-defined over the entire field, including steep flanks by the good quality seismic as a very continuous hard kick over the entire flat-topped platform. The northern and eastern flanks of the structure are steep compared to the gentler dips towards the southsouthwest (Fig. 2).

The gas accumulation in the Miocene carbonates has contaminants with the presence of $\mathrm{CO} 2$ and $\mathrm{H} 2 \mathrm{~S}$. The reservoir section encountered in this well is showing heterogeneous 


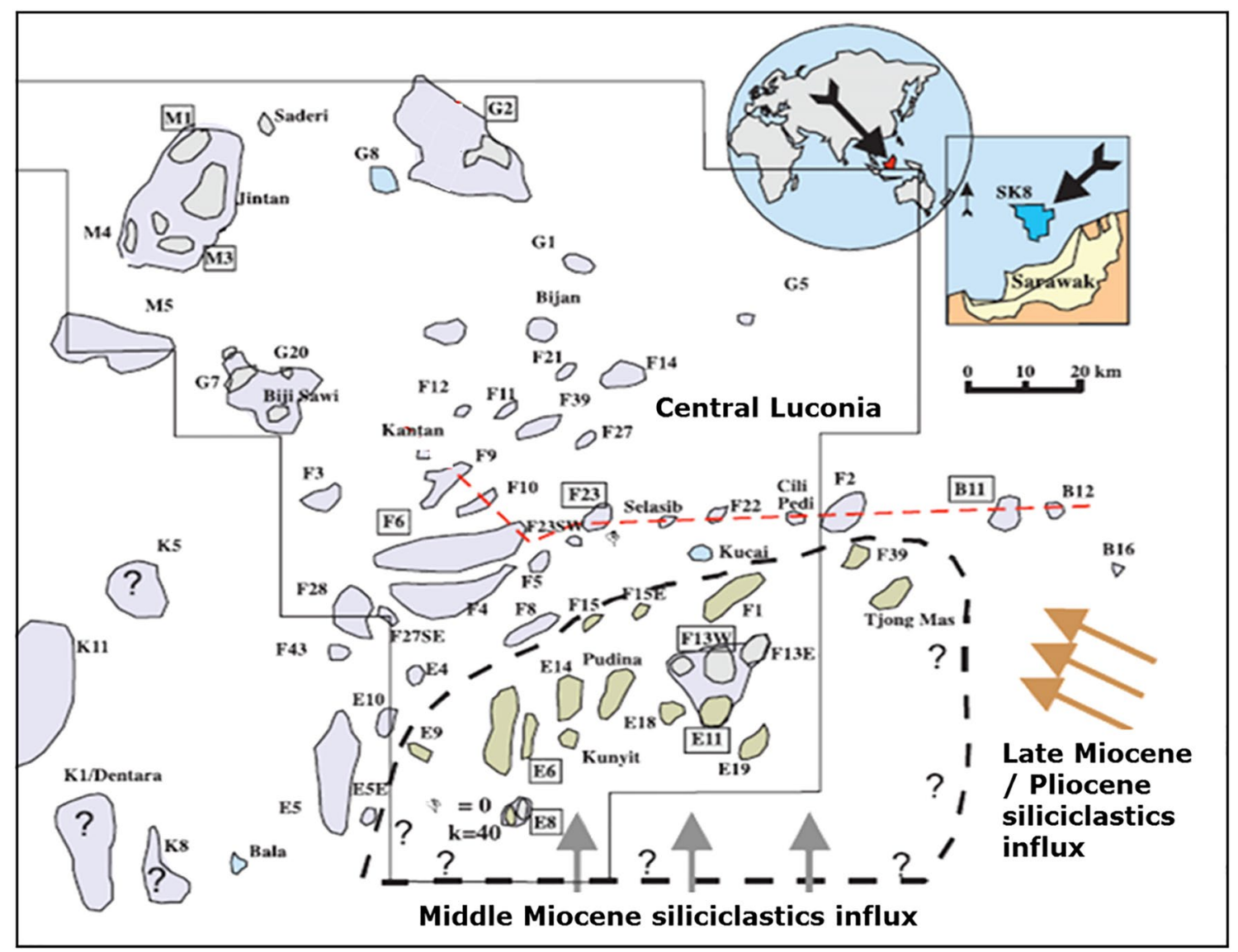

Fig. 1 Central Luconia province, with the direction of middle Miocene siliciclastic influx deposition and Late Miocene to Pliocene siliciclastic influx. The red dotted line is the regional cross section shown in Fig. 2

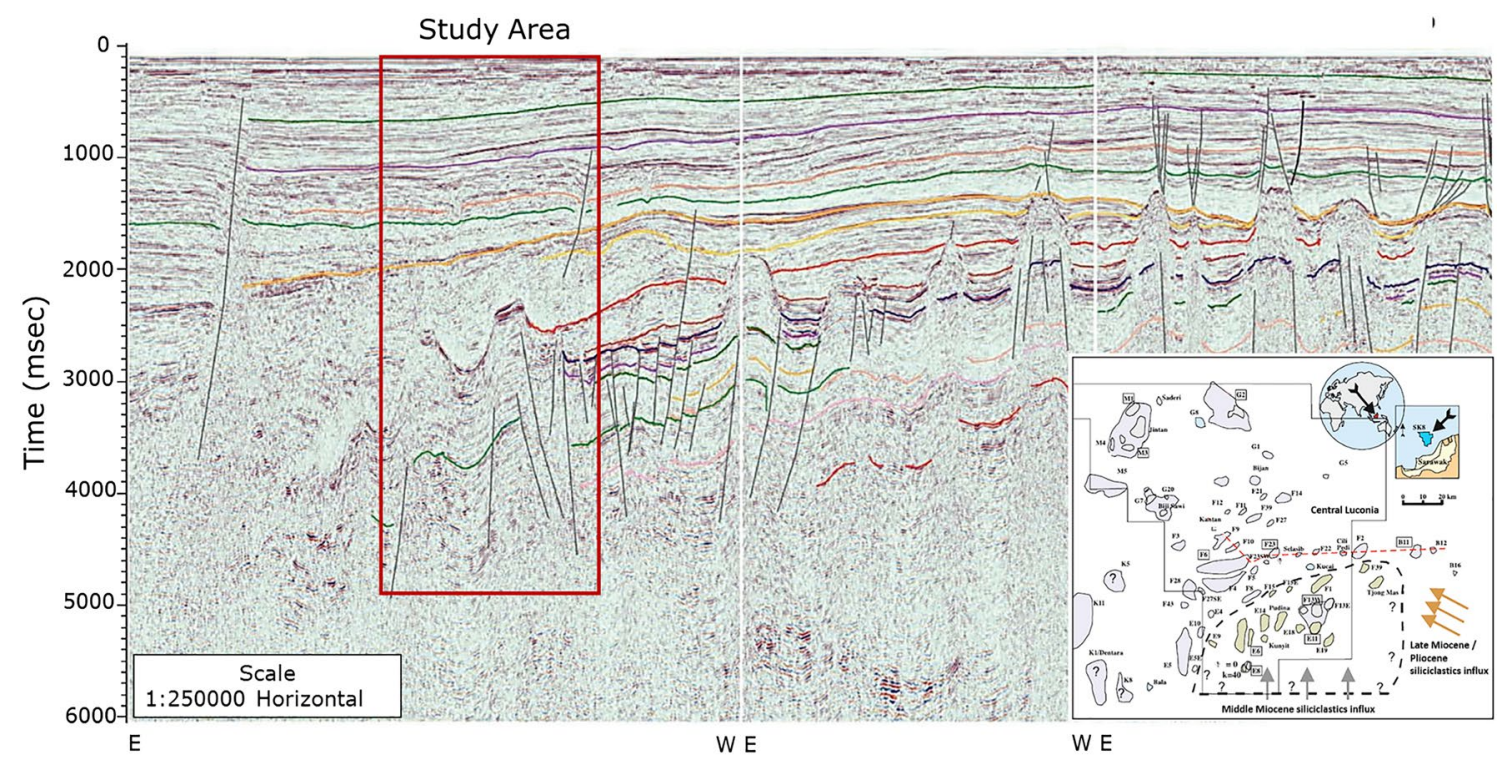

Fig. 2 The regional seismic profile showing growth architecture, faulting, and Karstification of a middle Miocene Carbonate platform. The study area is under the red box (Vahrenkamp et al. 2004) 
nature with significant variation in reservoir properties depending on preserved porosity types and facies association. Depositional architecture and seismic expression in carbonates of the study area have revealed layered internal disposition represented by continuous, high-amplitude reflection characters inferring deposition under relatively low energy conditions in the interior parts of the field. The cyclic development of carbonates in the reservoir interval is interpreted to be controlled by relative sea-level fluctuations and subsidence of the depositional area. Interpretation result indicates relatively poor reservoir quality in the depressed lagoonal area in the central part of the structure in the vicinity of exploration well 1 as compared to the western and southern parts of the structure where better reservoir quality is expected due to deposition of high-energy facies in structurally higher position and subaerial exposures with fluctuation of sea levels.

\section{Geology of the area}

Luconia Province is a broad and generally stable part with a wide shelf in the Sarawak Basin, offshore Borneo. The present-day bathymetry of the Central Luconia region varies from $60-140 \mathrm{~m}$. It passes to the north-northeast into the continental slope, and ultimately the South China Sea abyssal zone. The area was shaped by regional extension and sea-floor spreading in the South China Sea starting in the Oligocene (Taylor and Hayes 1983). This extension established a regional pattern of horst and graben structures, and although the age of the end of sea-floor spreading is debated (Taylor and Hayes 1983), it is generally considered to persist into the Early Miocene. By the Middle Miocene, compressional phases, perhaps associated with the Sabah Orogeny of the Balingian Province to the south (Lunt and Madon 2017; Rankey et al. 2019), sporadically influenced Central Luconia.

The Central Luconia carbonate platform developed on a fault-bounded regional structural high as the area was free from clastic supply due to its structural position. Luconia platform is limited to the north by the present-day shelf edge, while the western, southern, and eastern boundaries are delimited by geological provinces of Tatau Horst and Graben, Balingian, and Baram Delta, respectively (Madon 1999). The middle to late Miocene witnessed a major period of carbonate deposition that shows a relatively low degree of deformation, indicating a stable basement and low tectonic activity. The growth of carbonate platform with reefal body initiated on pre-existing structural highs formed during Late Oligocene rifting as the area was free from the clastic influx.

Initially, the carbonate deposition was able to keep up with the rate of subsidence resulting from the existence of pinnacle reefs on pre-existing structural highs, whereas the deltaic deposits reflect an overall transgression of the coastline towards the west and south. The combined effects of subsidence of the area due to post-Miocene tectonic activities and eustatic sea-level rise have resulted in the ultimate demise of carbonate deposition in the Central Luconia platform including the study area. The reefs were eventually buried by fine siliciclastic sediments of the Baram delta complex that prograded from the southeast during the Late Miocene to Recent.

The interpretation of seismic data has confirmed the end of carbonate growth in the study area relatively early due to its depositional set-up. The carbonate build-ups are shortlived in the south compared to the North in the Luconia platform which can be explained due to clastic sediment influx in the basin and its provenance. In general, high-energy carbonates with better reservoir characters are deposited in the fringe of the carbonate build-ups, whereas the interior area has experienced the deposition of carbonates under relatively low energy conditions with poor reservoir quality.

\section{Results and discussions}

\section{Data, material and methods}

In this research, Petrel software is used for data interpretation, and Hampson Russell for seismic inversion. Data with a suitable format such as seismic and well-logging data of SEG-Y and LAS, respectively, is provided for this study. Figure 3 a shows the seismic interpretation window in which a top Carbonate with the blue horizon and a base Carbonate with the purple horizon is picked. These two seismic horizons delimiting the reservoir section units in the study area were selected for seismic inversion. The acoustic impedance $\log$ is calculated by multiplying the sonic and density $\log$ in a well location. In a seismic inversion, the most significant step is wavelet extraction, a suitable seismic wavelet extracted separately in the location of Well-A. The wavelet extraction and synthetic seismogram were repeated constantly until the correlation coefficient between the synthetic and the real seismogram become acceptable with minimal errors in the well location.

In this study, the designation "isolated carbonate platform" refers to a thick and mappable sequence of carbonates separate from the main landmass. Isolated carbonate platforms are differentiated from carbonate buildups are featured with significant topographic relief located in the platforms (Schlager 2005). The isolated carbonate platform is recognized based on diagnostic criteria defined by (Burgess et al. 2013) such as a positive antecedent topography, marked stratal thickening, high angle flanks, stacking patterns, distinct reflection amplitude, and geometry, and onlaps of surrounding sediments. Middle to Late Miocene 

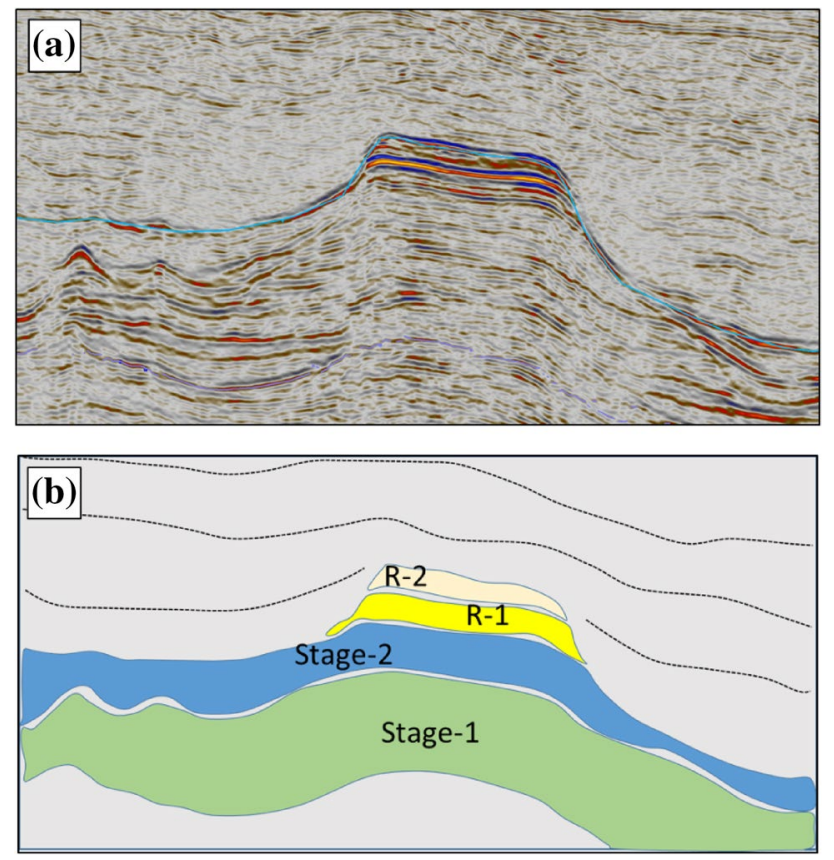

Fig. 3 Summary of Geometric evolution of the field a) Seismic line with interpreted two horizon top and base Carbonate and b) interpretive representation of line in between Carbonate with Stages and Reservoir

time has witnessed the development of numerous isolated carbonate platforms in the Central Luconia province of offshore Sarawak. Miocene carbonates are deposited on faultbounded structural highs produced largely by extensional tectonics followed strike-slip deformation at later phase. The carbonate platforms in the Central Luconia province were eventually buried by siliciclastic influx of the Baram delta complex that prograded from the southeast and provide a regional seal for hydrocarbon entrapment.

From the seismic data in Fig. 3a, several stages of deposition of carbonates are observed in isolated carbonate platforms in response to Miocene tectonic activities, syn-depositional deformation, and bathymetric fluctuations. Figure $3 b$ illustrates the evolution of this platform and adjacent basinal strata and reveals the depositional story of the carbonates in terms of phases of growth, the influence of tectonics, and the nature of the platform flanks.

\section{Well to seismic tie and surface}

The workflow of this research started with the establishment of a regionalgeology from a regional seismic line which shows the isolated carbonate platforms and continental shelf margin. Based on the identification of the significant key surfaces in the seismic profiles corresponding to the top and base of the carbonates reservoir, the two (2) surface maps were generated using the well data from two (2) exploratory

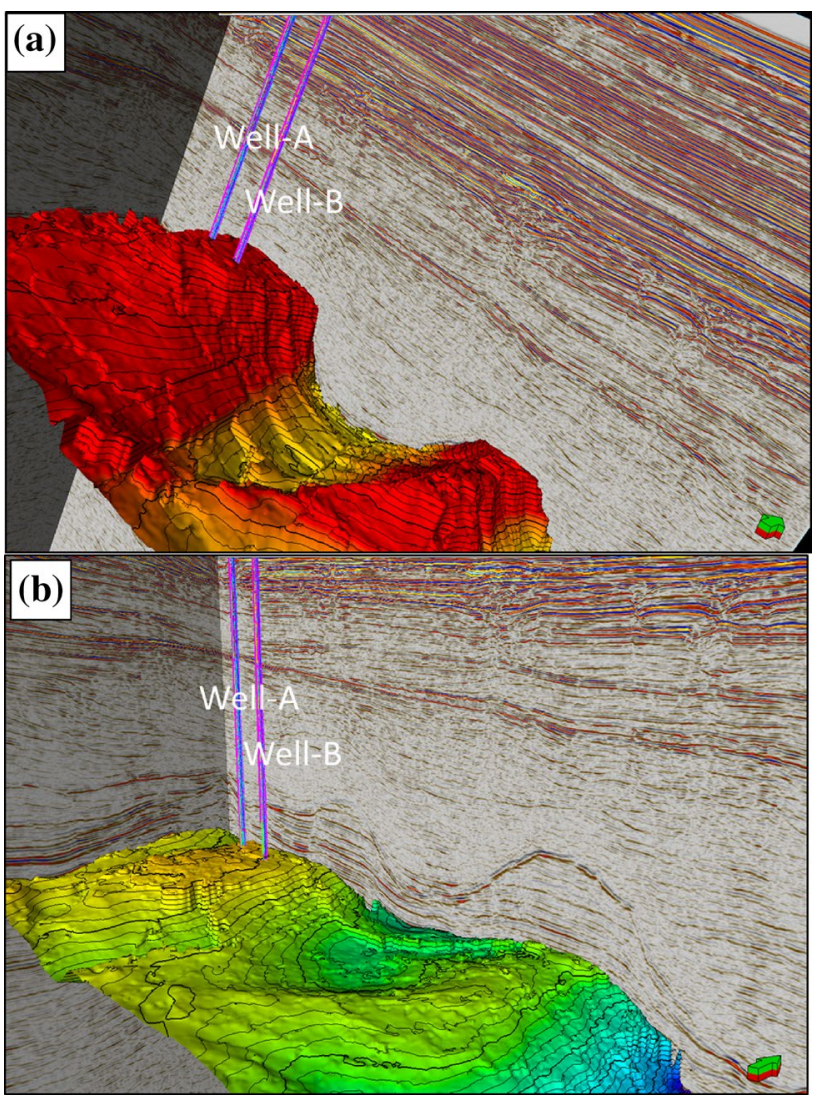

Fig. 4 a 3-D surface map view of the top carbonate interpreted section. Two platforms can be seen which might be the producing reservoir. The study focused in this paper is on the left platform, and b 3-D surface map view of base Carbonate interpreted section. The well A and $\mathrm{B}$ are overlaid on the seismic display

wells as shown in Fig. 4a and b. These two wells are drilled on the desired uplifted area to explore hydrocarbon in the carbonate buildup. Wireline logs were calibrated with lithological and biostratigraphy data obtained from cuttings of the drilled wells. Vertical seismic profile (VSP) and checkshot data were utilized to calibrate the wells with 3D seismic lines. The exploration of well-1 and well-2 were drilled in the apex of a drowned isolated carbonate platform. The well penetrated two major stratigraphic units and reservoirs as shown in Fig. 3b.

On the 3D seismic, a persistent and High-amplitude seismic horizon is mapped as to the Top Carbonates (Fig. 4a) which is a sharp transition between limestone and overlaying siliciclastic and coincides with the drowning unconformity (DU). The lower boundary of the Carbonate succession was established as Base Carbonate by identification of the highamplitude seismic reflection and with well correlation, as shown in Fig. 4b.

Seismic transects across the field of study are interpreted based on seismic reflection characters and identified the deposition of major sedimentary units such as siliciclastic

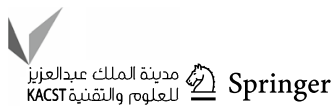


and carbonates. The depth of the carbonate platform 1 and platform 2 is about $2.2 \mathrm{~s}$ in the seismic section in Fig. 5. Further, the distribution of carbonate is about $100 \mathrm{~m}$ laterally and but if we observe in the cross-line which is Fig. 5c, the carbonate distribution is $10 \mathrm{~m}$. The integration of geological, geophysical, and petrophysical data confirmed the carbonate reservoir is subdivided into two parts which are separated by intervening tight layer as shown in Fig. 6.

\section{Seismic facies}

There are a few seismic facies that can be identified from this data set and it can be differentiated by the internal reflection configuration and external geometry of the carbonates. Interpretation of the depositional environments of each facies is identified based on the study performed by (Shahzad et al. 2019) in a similar carbonate depositional setting. A summary of each facies is provided and a description of some of the seismic facies that were identified from the seismic data sets is explained in Table 1. The seismic facies are identified based on distinct reflection geometry which is linked with the depositional environment of the facies.

\section{Seismic data reconstruction}

Inversion results help to capture the lateral facies and porosity variation in the reservoir section across the field for better visualization and estimation of reservoir parameters to address the uncertainties associated with field development. The study reveals that the reservoir heterogeneity is mainly due to depositional facies variation across the field and the
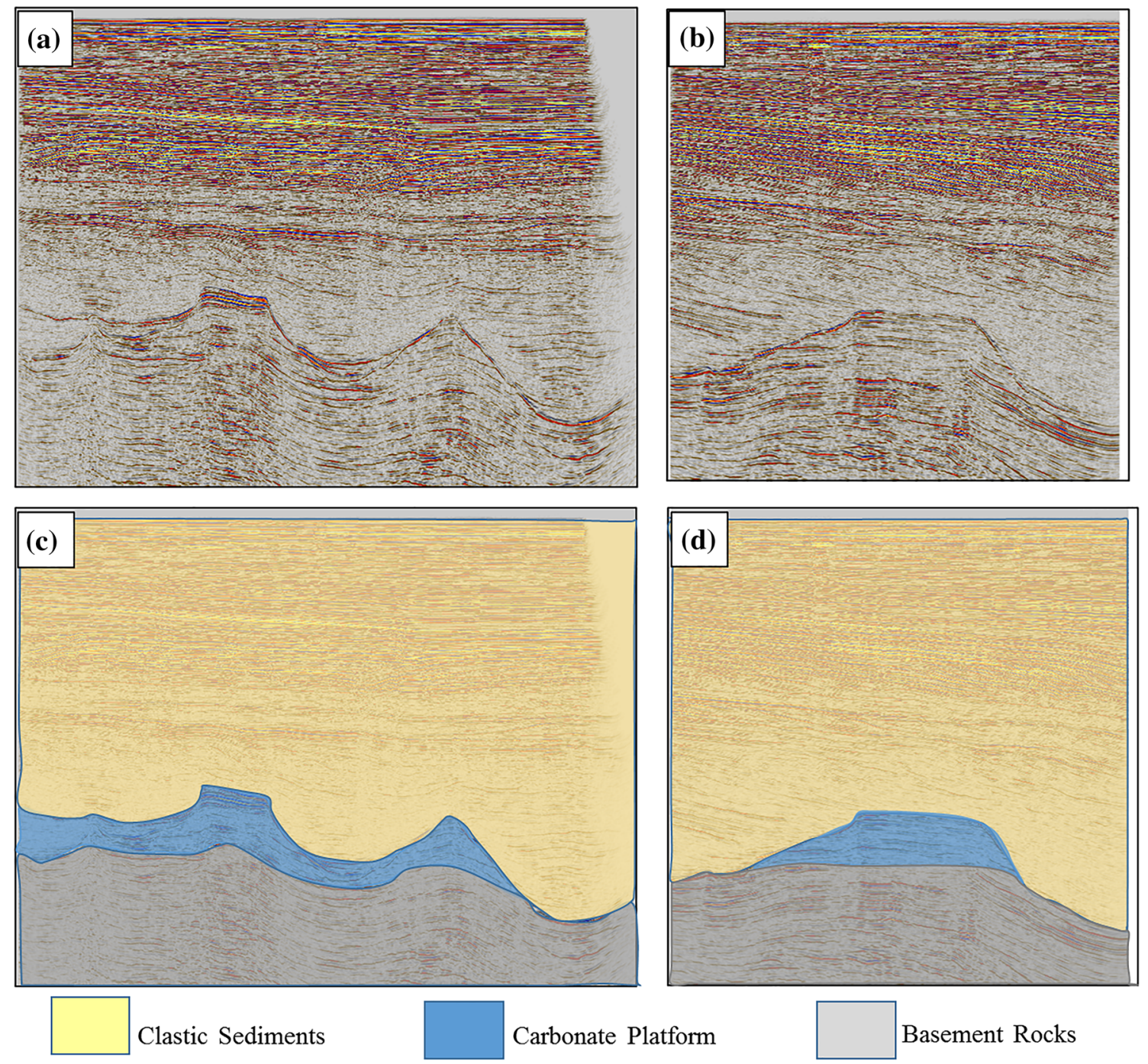

Fig. 5 a-d Seismic transects across the carbonate platforms in the north-south and east-west direction. Carbonate platforms are separated by depositional lows 


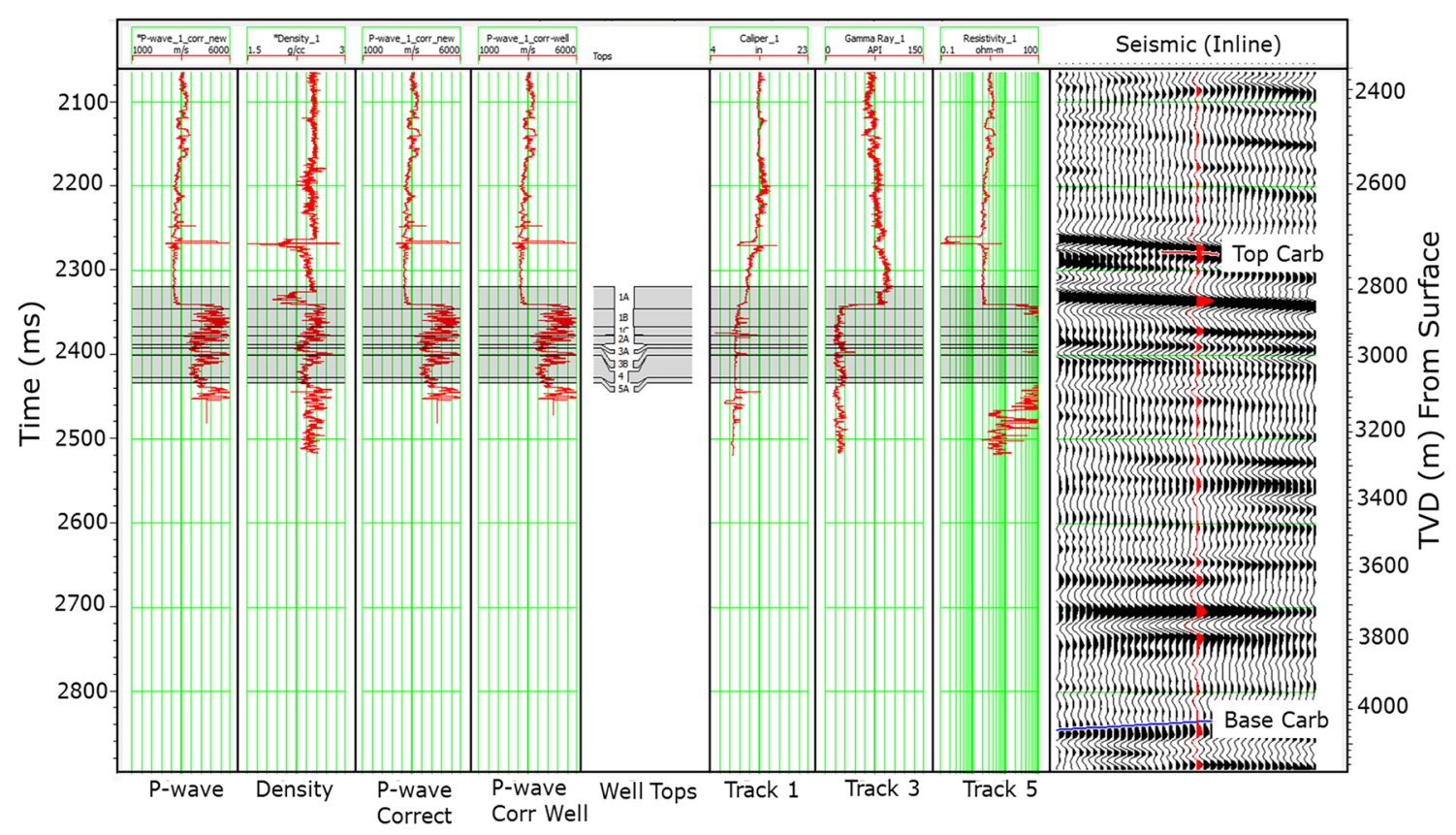

Fig. 6 Logs correlations and display of P-wave and density after and before correction. Also the gamma-ray and resistivity log display

effect of diagenetic changes from the nature of exposure that the carbonates have periodically experienced due to sealevel fluctuations. Integration of geological and geophysical data indicates that relatively higher porosity is expected in the reefal build-up area towards the west, along the south $\&$ eastern margin than the depressed lagoonal area of the central part of the structure and northern part of the field. The facies variation in carbonate reservoirs has an impact on hydrocarbon reserves and production behavior in this field. Based on the present interpretation, considerable porosity variation is observed away from the wells drilled in the central lagoonal area and there is potential for increased porosity away from the wells due to better development of reservoir facies under favorable conditions. The inversion result has identified the layers with better porosity in the reservoir section and distribution of a tight layer that acted as a permeability barrier across the field. The present study also corroborates the earlier view that the preserved porosities are facies selective and mostly secondary in nature due to the effect of diagenesis.

\section{Seismic inversion}

After the selection of the model-based inversion method for the seismic post-stack inversion process, the results show in Fig. 7 the acoustic impedance contrast with the interpretation of reservoir tops. The seismic inversion process has enabled us to image the thin-bed within the reservoir layer, which has been capture by the well-logs but in the seismic impedance the layer strata are missing. This could be an image by the re-processing of the legacy data set with inverted Vp in which well-log frequencies are used. Prior to performing the Seismic inversion, a log correlation is performed for defining the check shot of the strata within the reservoir, which is subdivided into 5 sub-elements within the reservoir column as shown in Fig. 6. For interpretation, we chose two horizons based on the log correlation of top and base of carbonate which later was the input for seismic inversion.

The present study is useful to reduce the uncertainty of the key subsurface parameters that have a strong bearing on field performance. Application of modern techniques in interpretation has a greater impact to optimize the number of wells with proper placement in the sweet zone to ensure better well deliverability and thus to reduce the project cost and enhance the chance of economic viability of the project.

Integration of geological, petrophysical, and geophysical data derived from seismic inversion has helped for better delineation of reservoir facies and reservoir characterization. The interpretation result indicates that relatively higher porosity is expected in the reefal build-up area towards the west, along the south \& eastern margin than the depressed lagoonal area of the central part of the structure and northern part of the field which has an impact on hydrocarbon reserves and production behavior in this field.

\section{Microfacies analysis}

Microfacies analysis of cuttings and cores has confirmed the lithology is represented by predominantly limestone with the

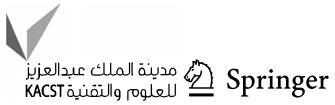


Table 1 Catalog of seismic facies recognized in the high-resolution seismic data set in the Malaysian Carbonates field

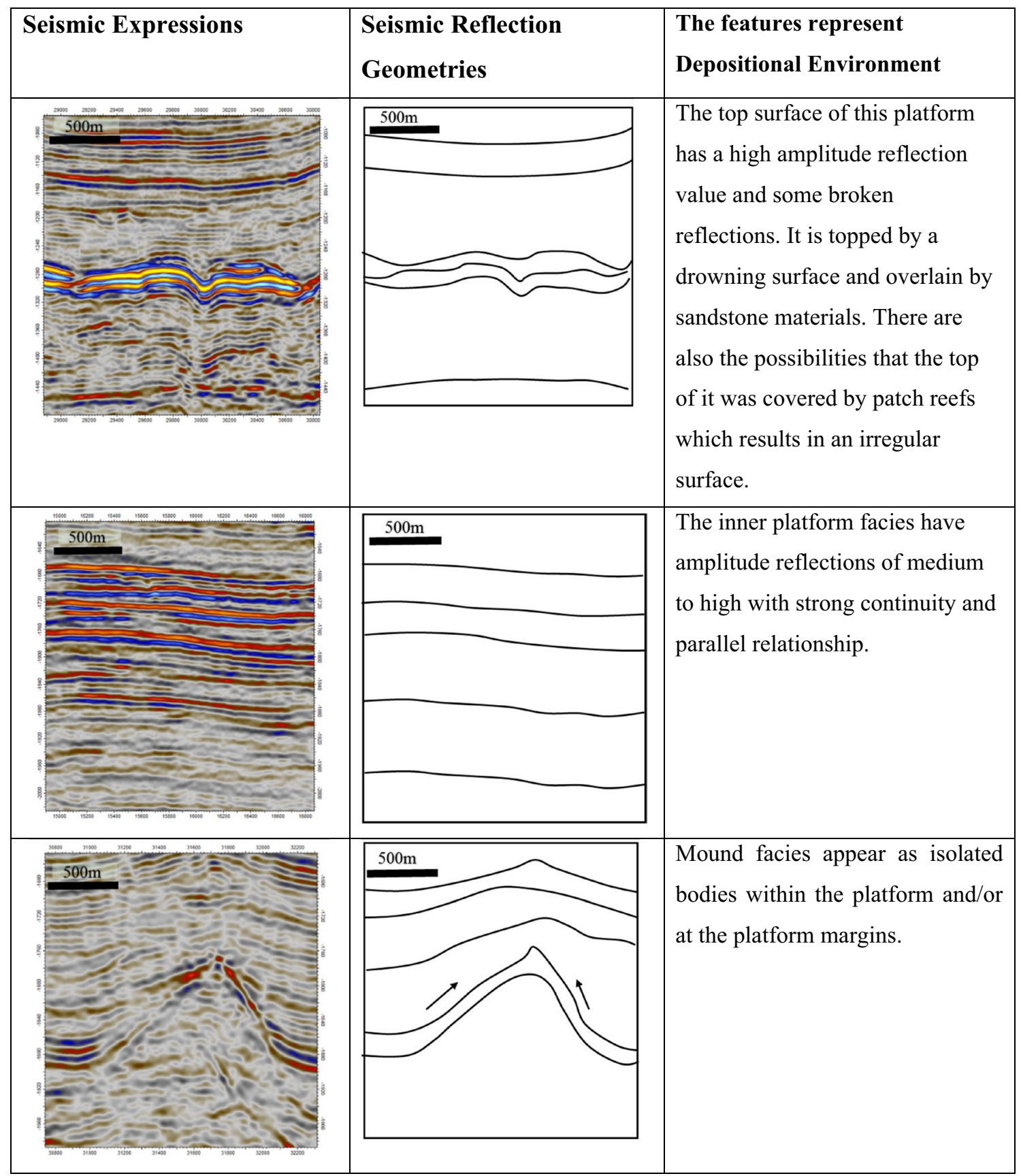

minor occurrence of dolomitic limestone. Previous works have identified four major facies types in Luconia carbonates which are represented by moldic limestone, chalky moldic limestone, chalky limestone, and tight limestone. The moldic and chalky moldic limestone are grain-supported limestone deposited in shallow marine conditions having betterpreserved porosity in the range of 13 to more than $15 \%$. Most of the preserved porosity is secondary in origin due to solution activities and represented by molds, vugs, solution enlarged intergranular, and fine interparticle porosity.
Chalky limestone is characterized by predominantly fine interparticle porosity around 9 to $10 \%$ having poor to fair reservoir properties. The tight limestone is represented by well-cemented relatively low energy facies represented by mainly wackestone and stylolitic packstone. Minor leaching is observed along the stylolite due to the passage of corrosive fluids along the stylolitic plane which is limited to thin zones. Microfacies analysis of the carbonates has confirmed that the porosity generation in porous and permeable reservoirs is mainly due to solution activity in selective zones 
Table 1 (continued)

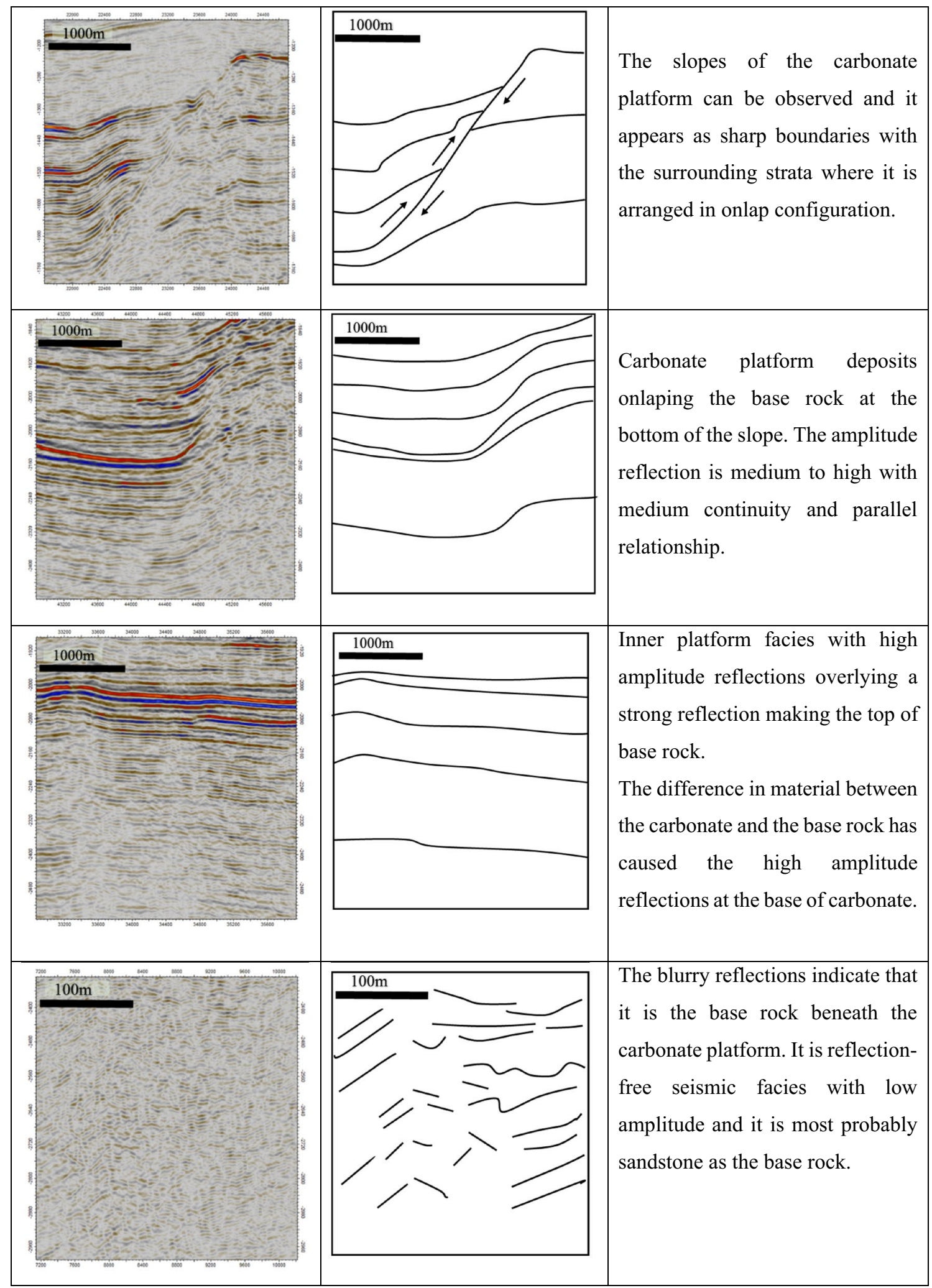

controlled by depositional facies and diagenetic changes. Cyclic deposition of carbonates and facies variation both temporally and laterally due to depositional conditions with intermittent subaerial exposures and multiphase diagenetic 


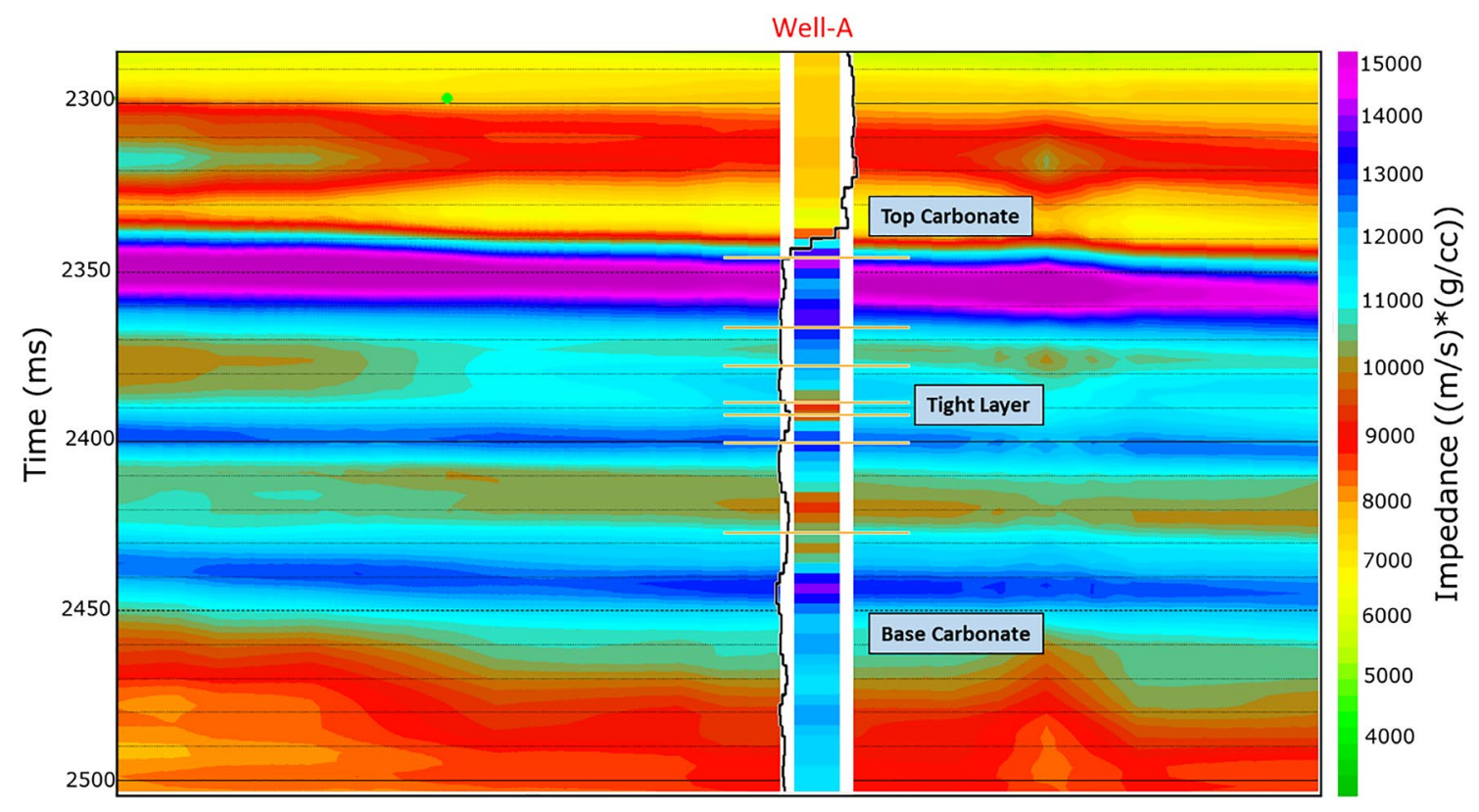

Fig. 7 Inverted Impedance contrast using seismic post-stack model base inversion. The correlation of well log and seismic is improved but the tight layer is not illuminated in inverted data

changes have contributed to reservoir heterogeneity. Preserved porosity types and its distribution are quite varied in carbonates reservoirs in this field that needs special attention with better imaging with higher resolution for field development and management.

The key uncertainties that need to be addressed in the study area include reservoir heterogeneity, porosity- permeability variation across the field, movement of fluids with associated contaminants across the tight layer separating the upper and lower reservoirs, and the possible aquifer strength. The aquifer strength has a direct link with the available porosity and lateral continuity of the tight layer within the reservoir sequence. The uncertainties relating to a structural definition based on present seismic data are relatively small compared to the other uncertainties mentioned above. The uncertainty related to porosity-permeability in reservoir intervals needs to be addressed with the application of modern interpretation tools like seismic inversion as it has a significant impact on the well deliverability and thus to decide for optimum well positions in sweet zone. Based on well and seismic data the reservoir sequence in the study area can be subdivided into 5 main units labeled Zones 1-5 which are based on porosity cycles as shown in the electrofacies correlation of the wells (Fig. 8).

Well data confirms the presence of about $11.0 \mathrm{~m}$ tight zone (zone $3 \mathrm{~A}$ in well log interpretation) within the Miocene carbonate reservoir that separates the hydrocarbon accumulation in this field into an upper and lower reservoir (Fig. 8). The tight layer will act as a baffle to flow throughout the field depending on its lateral continuity across the field. The effectiveness of this tight layer across the field will control the flow of gas and its associated contaminants from the lower reservoir to the upper reservoir as well as aquifer support with a greater impact on field development. It is possible that the tight layer may be breached due to pinch out of the strata or subaerial exposure and erosion of zone $3 \mathrm{~A}$ in paleo-high areas during sea-level lowstand creating a window in the tight zone to facilitate the movement of fluid from lower to an upper reservoir. This tight zone is seismically expressed by a strong and continuous hard event across the field. It is highly desirable to map the tight zone seismically across the field to confirm the lateral continuation over the field as a lower reservoir section having a higher level of contaminants and overall poorer reservoir properties.

Understanding the effectiveness of the tight layer as an effective permeability barrier with advanced techniques is immense as the contaminants which are represented by $\mathrm{CO}_{2}$ and $\mathrm{H}_{2} \mathrm{~S}$ in this field have a significantly higher concentration in the lower reservoir compared to the upper reservoir. It is planned to exploit gas from this field initially from the upper reservoir layers with higher porosity and permeability and lower contaminant concentration with an expectation that the intervening tight layer will act as a permeability barrier. It may be necessitated for additional well drilling to exploit the lower reservoir as the presence of an effective permeability barrier will restrict the flow of fluids from the lower reservoir to the upper reservoir as shown in Fig. 8. It will incur an additional cost of drilling that will definitely impact the economic value of the project. In addition, the characterization of the aquifer zone by estimating the 


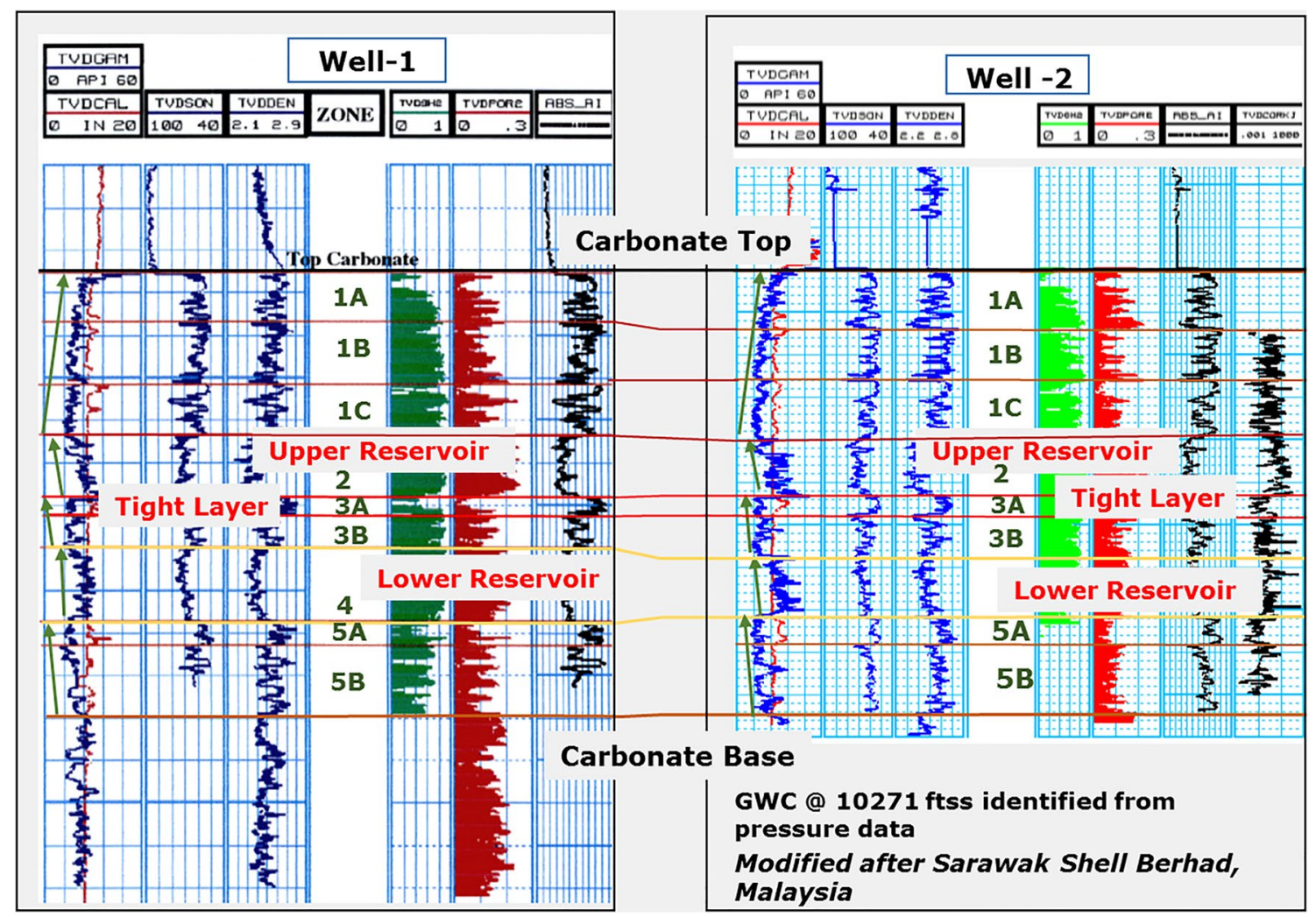

Fig. 8 Electrofacies correlation showing the distribution of reservoir layers separated by a tight layer in the study area

porosity distribution is very important to assess the quality of aquifer support and the design of water handling capacity for field management. To address the sub-surface key uncertainties as discussed above, a new approach is required in seismic interpretation for better understanding and decisionmaking process for field development and management. The seismic inversion process as discussed has enabled to the image of the thin-bed within the reservoir layer that has been captured by electrologs of the drilled wells in this field.

\section{Conclusions}

Integrated studies of seismic, geological, and petrophysical data and careful review of previous studies carried out in this area have helped to improve the understanding of the depositional history of carbonates, factors controlling reservoir heterogeneity, possible fluid flow models, and reservoir characterization for field development. The study has also helped to analyze the factors that have contributed to the evolution and demise of Middle to Late Miocene carbonate platforms in the Central Luconia Province of Sarawak Basin. Seismic characterization of Isolated carbonate platform succession and adjacent platform areas reveals a complex evolutionary history of the reservoir facies where tectonics, siliciclastic sediment supply, and bathymetric fluctuations have played an important role. The integrated study also assisted in the paleo-geographical reconstruction of the carbonate platforms in Luconia province for an improved understanding of reservoir facies and heterogeneity in carbonate reservoirs that may affect reservoir performance.

Interpretation of geological and geophysical data have identified different platform growth stages across the study area due to eustatic sea-level changes, and variations in subsidence caused by regional and local tectonics. Seismic inversion has enabled us to image the subsurface reservoirs better by identifying the lateral and vertical facies variation, striatal geometries, and the existence of a tight layer across the field that has divided the aquifer into two, the upper and lower reservoirs. Interpretation of seismic data revealed that the carbonate deposition was initiated on the pre-existing structural highs and the topographic relief has determined the size, shape, and location for the carbonate platforms in Central Luconia province. It is further explained that the carbonate platform architecture and the development of sweet spots in the reservoir rocks are the results of the combined effects of regional and local tectonics, differential tectonic subsidence, paleo-climatic condition, the siliciclastic influx in the basin, and eustatic sea-level changes. The low amplitude and high-frequency eustatic variations

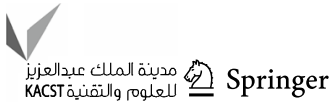


of the greenhouse world provided an ideal balance between the relative sea-level fluctuations and the rate of deposition. The present study has also explained that integrated studies of geological and geophysical data are necessary for reservoir characterization to identify the sweet spots for strategic well placement, both producers and injectors, for commercial exploitation of reservoirs, and economic development of the field.

Acknowledgements The authors would like to thank Universiti Sains Malaysia (USM), Universiti Teknologi PETRONAS (UTP), and the center for Seismic imaging for providing the facilities of this research. We could not perform the research without access to the data by PETRONAS. Schlumberger is thanked for providing licenses to their software Petrel to perform interpretation and CGG for Hampson Russell to achieve the seismic inversion results.

Funding The author(s) received no specific funding for this work.

\section{Declarations}

Conflict of interest The authors declare that they have no conflict of interest.

Open Access This article is licensed under a Creative Commons Attribution 4.0 International License, which permits use, sharing, adaptation, distribution and reproduction in any medium or format, as long as you give appropriate credit to the original author(s) and the source, provide a link to the Creative Commons licence, and indicate if changes were made. The images or other third party material in this article are included in the article's Creative Commons licence, unless indicated otherwise in a credit line to the material. If material is not included in the article's Creative Commons licence and your intended use is not permitted by statutory regulation or exceeds the permitted use, you will need to obtain permission directly from the copyright holder. To view a copy of this licence, visit http://creativecommons.org/licenses/by/4.0/.

\section{References}

Bashir Y, Babasafari AA, Biswas A, et al (2019) Cohesive approach for high-resolution seismic using inversion and imaging in malaysian carbonate field. In: International petroleum technology conference. International petroleum technology conference

Bracco Gartner GL (2000) High resolution impedance models of outcrops and their applications in seismic interpretation. Doctoral Thesis at VrijeUniversiteit Amsterdam

Burgess PM, Winefield P, Minzoni M, Elders C (2013) Methods for identification of isolated carbonate buildups from seismic reflection dataIdentification of Isolated Carbonate Buildups from Seismic Reflection Data. Am Assoc Pet Geol Bull 97:1071-1098

Epting M (1980) Sedimentology of Miocene carbonate buildups, central Luconia, offshore Sarawak. Bull Geol Soc Malays 12(1980):17-30

Epting M (1987) Active margin: miocene carbonate buildups of central Luconia. In: Bally AW (ed.) Offshore Sarawak AAPG Studies in Geology \#27, Atlas of Seismic Stratigraphy, vol. 3, pp. 168-173

Janjuhah HT, Alansari A, Ghosh DP, Bashir Y (2018) New approach towards the classification of microporosity in Miocene carbonate rocks, Central Luconia, offshore Sarawak, Malaysia. J Nat Gas Geosci 3:119-133

Lunt P, Madon M (2017) A review of the Sarawak cycles: history and modern application. Bulletin of the Geological Society of Malaysia, Vol. 63, June 2017, pp. 77-101

Madon M (1999) Geological setting of Sarawak. Pet Geol Resour Malaysia 273-290

Rankey EC, Schlaich M, Mokhtar S et al (2019) Seismic architecture of a Miocene isolated carbonate platform and associated offplatform strata (Central Luconia Province, offshore Malaysia). Mar Pet Geol 102:477-495. https://doi.org/10.1016/j.marpetgeo. 2019.01.009

Schlager W (2005) Carbonate sedimentology and sequence stratigraphy. SEPM Soc for Sed Geology 145(1):156

Shahzad K, Betzler C, Qayyum F (2019) Controls on the Paleogene carbonate platform growth under greenhouse climate conditions (Offshore Indus Basin). Mar Pet Geol 101:519-539

Taylor B, Hayes DE (1983) Origin and history of the South China Sea basin. Tecton Geol Evol Southeast Asian seas islands Part 2(27):23-56

Vahrenkamp VC (1998) Miocene carbonates of the Luconia province, offshore Sarawak: implications for regional geology and reservoir properties from strontium-isotope stratigraphy. Bulletin Geol Soc Malaysia. https://doi.org/10.7186/bgsm42199801

Vahrenkamp VC (2000) Sr-isotope stratigraphy of Miocene carbonates, Luconia Province, Sarawak, Malaysia: implications for platform growth and demise and regional reservoir behaviour. Bull Geol Soc Malays 42:1-13

Vahrenkamp VC, David F, Duijndam P, et al (2004) Growth architecture, faulting, and karstification of a middle Miocene carbonate platform, Luconia Province, offshore Sarawak, Malaysia

Wilson MEJ (2002) Cenozoic carbonates in Southeast Asia: implications for equatorial carbonate development. Sediment Geol 147:295-428

Zampetti V, Schlager W, van Konijnenburg J-H, Everts A-J (2004) Architecture and growth history of a Miocene carbonate platform from 3D seismic reflection data; Luconia province, offshore Sarawak, Malaysia. Mar Pet Geol 21:517-534

Publisher's Note Springer Nature remains neutral with regard to jurisdictional claims in published maps and institutional affiliations. 